Int. J. Dev. Biol. 55: 205-208 (2011)

doi: $10.1387 / \mathrm{ijdb} .113309 \mathrm{bn}$

\title{
A SET/MYND chromatin re-modelling protein regulates Dictyostelium prespore patterning
}

\author{
BEATRIZ NUÑEZ-CORCUERA, JOANNA BIRCH and JEFFREY G. WILLIAMS* \\ College of Life Sciences, Welcome Trust Building, University of Dundee, Dundee, UK
}

\begin{abstract}
SmdA is a Dictyostelium orthologue of the SET/MYND chromatin re-modelling proteins. In developing structures derived from a null mutant for smdA (a smdA-strain), prestalk patterning is normal, but using a prespore lac Z reporter fusion, there is ectopic accumulation of $\beta$-galactosidase in the prestalk region. As wild type slugs migrate, there is continual forward movement and redifferentiation of prespore cells into prestalk cells. Thus, a potential explanation for the ectopic reporter localization in smdA null prestalk cells is an increased rate of re-differentiation and anterior movement of prespore cells. In support of this notion, analysis of an unstable lacZ reporter, driven by the prespore promoter, reveals a normal staining pattern in the smdA- strain. We suggest that one or more genes regulated by SmdA acts to repress prespore re-specification.
\end{abstract}

KEY WORDS: Dictyostelium, SET/MYND, prespore, cell sorting

Developing Dictyostelium cells face two ultimate choices, to differentiate as spore cells or as stalk cells. These fates are presaged in the slug,that is formed halfway through development, by the differentiation of precursor cell types: prestalk cells and prespore cells. Most of the prestalk cells are situated in the anterior one-fifth of the slug, the prespore cells occupy the rear. These differentiation states are at the slug stage only quasi-stable. This can most clearly be demonstrated by dissecting the slug into its component prestalk and prespore regions. If sufficient time is allowed for redifferentiation, each part will form a proportioned culminant. This regulation mechanism presumably helps explain how Dictyostelium is able to maintain a remarkably constant stalk-spore ratio, over a $>1,000$ range of cell number.

PspA is a very commonly used marker of prespore cell differentiation. The transcription factors that regulate its expression have not been identified but a promoter region of $216 \mathrm{nt}$, that contains essential regulatory sequences, has been defined (Early and Williams, 1989). We synthesized this sequence in segments and used each in affinity chromatography. Two of the sub-regions purified a SET/MYND orthologue that we have named SmdA. The SET/ MYND domain sub-family of SET proteins is conserved in organisms ranging from yeast to vertebrates but has not hitherto been studied in Dictyostelium. The SET domain of vertebrate Smyd1 and Smyd3 catalyse methylation of histone $\mathrm{H} 3$ on lysine K4 (Hamamoto et al., 2004; Tan et al., 2006). Smyd2 dimethylates H3-K36 and also methylates the p53 tumour suppressor protein (Brown et al., 2006; Huang et al., 2006). In general Smyd proteins are thought to bind indirectly by interaction with other transcription factors, e.g. the oestrogen receptor (Kim et al., 2009), but Smyd3 acts as a direct DNA binding protein (Hamamoto et al., 2004).

We generated a null strain for SmdA but can find no effect on the total level of $p s p A$ expression, suggesting either that the purification of SmdA was serendipitous or that any effect is very subtle. There is a marked effect on prespore patterning but this aberration is only observed using a stable $p s p A$ reporter. This leads us to suggest a role for SmdA in stablilising prespore cell differentiation.

\section{Results}

\section{Identification of SmdA}

When the $p s p A$ promoter was subjected to deletion analysis a region, between -338 and -122 , was defined that contained essential regulatory elements near its boundaries (Early and Williams, 1989). In order to identify transcription factors that interact with the -338 to -122 region, it was synthesised as 4 sub-regions and each was used in affinity chromatography (B.N-C., J. B. and J. G. W., unpublished results). Among the proteins purified by two

Abbreviations used in this paper: SMD, SET/MYND protein.

\footnotetext{
*Address correspondence to: Jeffrey G. Williams. College of Life Sciences, WelcomeTrust Building, University of Dundee, Dow St., Dundee DD1 5EH, UK. Fax: +44-1382-344-211. e-mail: j.g.williams@dundee.ac.uk
}

Supplementary Material (one figure) for this paper is available at: http://dx.doi.org/10.1387/ijdb.113309bn 


\section{SmdA}

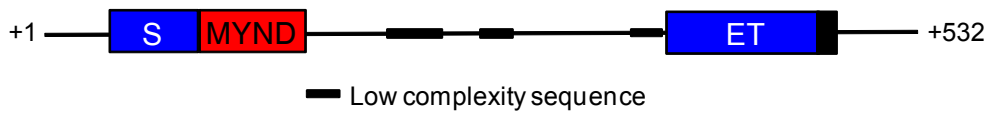

$\mathbf{S}$

$\begin{array}{llll}\text { SMdA } & 27 & \text { IEVKSVSEKGRCVFSKKFIPKGTMVFRDIPYAAIVDNQFKRNI } & 69 \\ & +\mathrm{EV}+\mathrm{KGR}++\mathrm{K}+\mathrm{F}+\mathrm{Y}+\mathrm{A}+\mathrm{V}+\mathrm{+}\end{array}$

SMYD1 9 VEVFTAEGKGRGLKATKEFWAADIIFAERAYSAVVFDSLVNFV 51

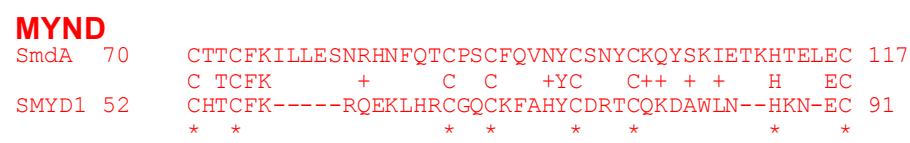

ET

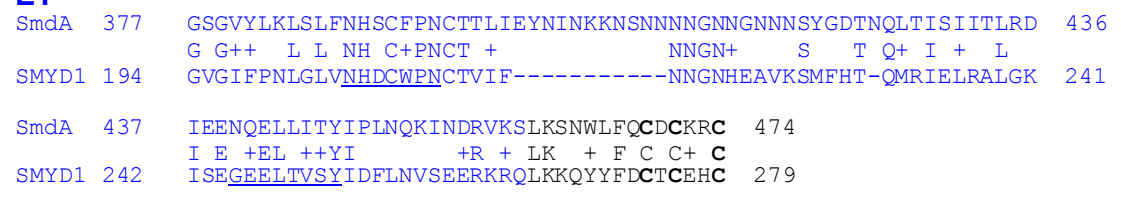

POST-SET

SMdA: SET and MYND domain containing protein 1, D. discoideum DDB_G0288495 SMYD1:SET and MYND domain containing 1, isoform CRAa [H.Sapiens] Āc.no. EAW77077

Fig. 1. Domain organization of the SmdA protein and sequence alignment of its conserved domains with Smyd1. The top panel is a representation of the domain organization of the Dictyostelium SmdA protein (dictyBase ID: DDB_G0288495). The split SET domain is shown in blue; the MYND domain is represented in red and the post-SET domain is displayed in black. The lower panel is a sequence alignment of the three conserved domains present in Dictyostelium SmdA with human Smyd1 (isoform CRAa, acc no: EAW77077).

of the regions (-291 to -163 and -122 to -168$)$ was a protein annotated as a Smyd ortholog at dictyBase (no. DDB_G0288495). We name the protein SmdA and Fig. 1 is an alignment of SmdA with human Smyd1.

Smyd proteins contain a SET domain that is split into two parts, (designated S and ET in Fig. 1) by the MYND domain. The SET domain of Smyd1 spans positions 24 to 454 and mediates lysinedirected H3 methylation. Histone methyltransferase activity is dependent on the amino acid sequence NHSCXPN and the presence of the cysteine-rich post SET domain at the $\mathrm{C}$ terminus (Rea et al., 2000). Both domains are conserved in SmdA. The MYND domain spans from amino acid position 70 to 116 in Smyd1. It is a predicted zinc-binding domain, defined by 7 cysteine residues and a single histidine residue, arranged in a $\mathrm{C} 4-\mathrm{C} 2 \mathrm{HC}$ configuration. All are conserved in SmdA (asterisked in Fig. 1). The Dictyosteliumgenome encodes six other, annotated Smyd orthologs. The database of gene expression profiles, at dictyBase ("dictyExpress"), indicates that the smdA mRNA is strongly developmentally regulated, with a peak at about $16 \mathrm{hr}$ of development and it is approximately threefold enriched in prespore over prestalk cells.

\section{SmdA is dispensable for growth, morphological development and prestalk patterning}

smd $A$ was inactivated, by replacement of the SET and MYND domains with a blasticidin resistance cassette using homologous gene replacement (Supplementary Fig. 1). Disruption was confirmed by PCR of genomic DNA and by RT-PCR on RNA from growing cells. One of the resultant null strains, Ko2, was designated the smdA- strain and was used in subsequent experiments. The strain grows and develops apparently normally (data not shown). It was transformed with prestalkspecific lacZ reporter constructs (Gaudet et al., 2008): ecmAO:gal (a marker of pstA, pstO and pstO/ALC differentiation) ecmO:gal (a marker of pstO and pstO/ALC differentiation), ecmA:gal (a marker of pstA differentiation), and ecmB:gal (a marker of pstAB and pstB differentiation). The smdA- strain expresses all four reporters with a normal pattern (Fig. 2).

\section{The patterning of a stable prespore marker becomes aberrant in the smdA-strain}

Since SmdAwas purified using sequences from within the $p s p A$ promoter, we quantitated $p s p A$ expression in parental and smdA- slug cells by $Q$ PCR. The value for the mutant is normalized to that of $A x-2$ and the mean is shown with the Standard Deviation $(n=3)$. There is no significant difference. The smdA- strain and parental Ax-2 cells were transformed with pspA:lacZ, to determine whether there is a patterning defect. In Ax-2 the construct is, as expected, predominantly expressed in the prespore region (Fig. 3B). However, in the smdA- strain high-level expression extends to the very tip of the slug. This is a clonal population of a reporter transformant but the same pattern was observed in two independently generated transformant pools (data not shown).

We initially suspected that SmdA might be required, as a corepresssor, to prevent $p s p A$ expression in prestalk cells at the slug stage. However, the explanation is more complex. Parental slugs

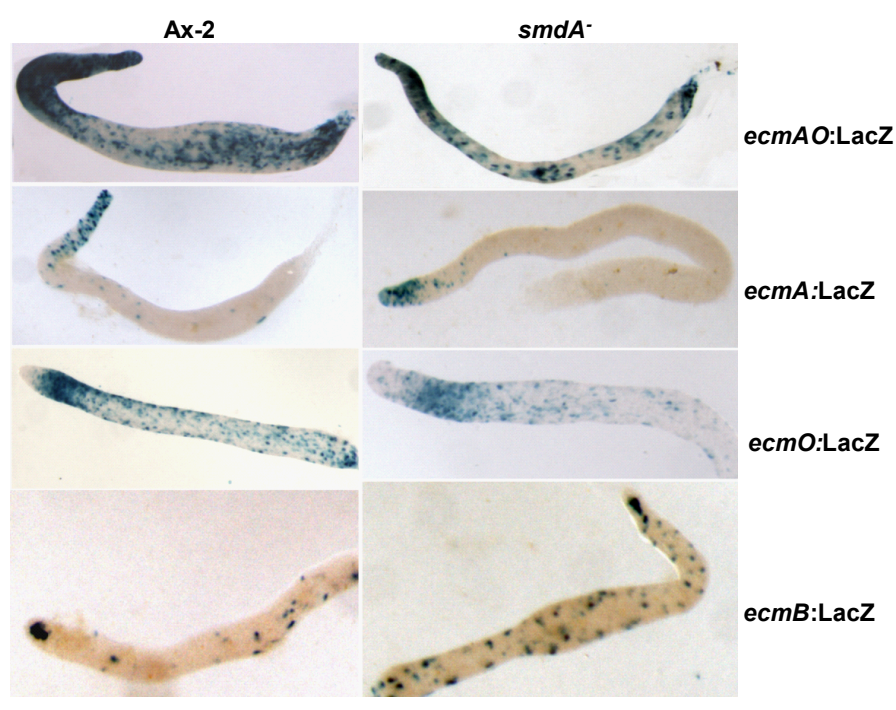

Fig. 2. Analysis of prestalk-specific gene expression in parental and smdA- slugs. $A X-2$ and smdA-cells, transformed with the indicated prestalk specific markers were developed to the slug stage and stained for $\beta$-galactosidase. 

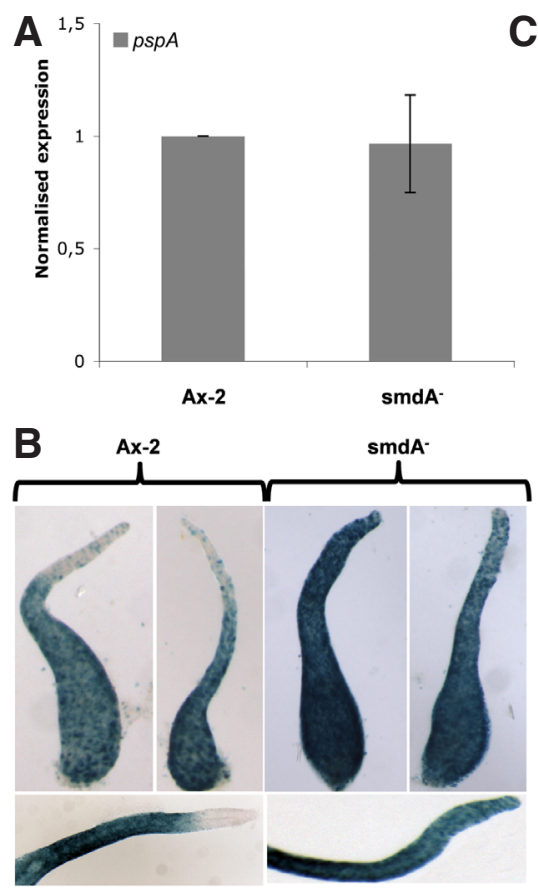

pspA:LacZ
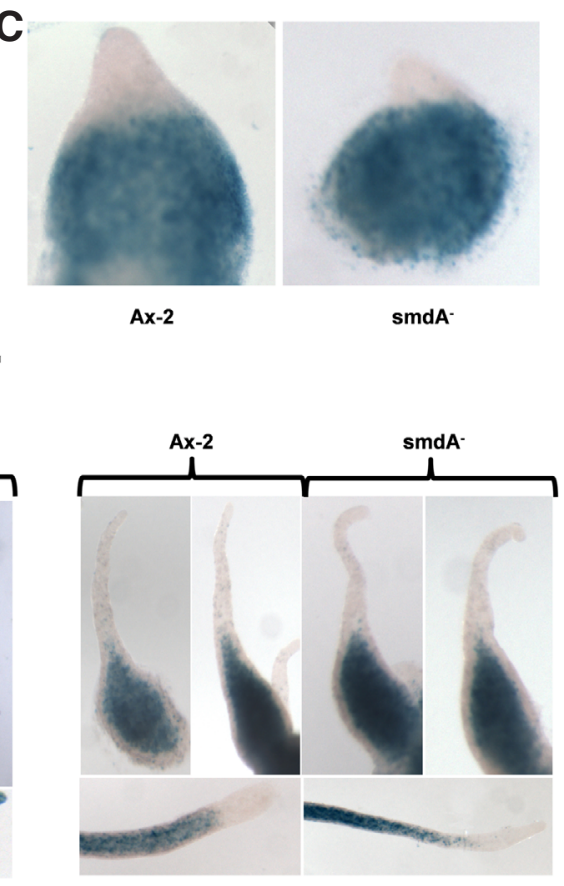

pspA:ileLacZ

Fig. 3. Analysis of prespore-specific gene expression in smdA- slugs. $A X-2$ and smdA-cells were developed to the slug stage. RNA was extracted and analysed by $Q$ $P C R$ to determine the level of pspA expression. The value for the mutant is normalized to that of $A x-2$ and the mean is shown with the standard deviation $(n=3)$. $A X-2$ and smdA-cells, transformed with the prespore markers pspA:gal (left) or pspA:ile-gal (right) were developed and stained for $\beta$-galactosidase. For both reporters the four images at the top are of first fingers while the two at the bottom are of migrating slugs. AX-2 and smdA-cells, transformed with pspA:gal were developed to the tipped mound stage and stained for $\beta$-galactosidase.

expressing stable prespore-specific reporter proteins show a clear demarcation of unstained prestalk cells from stained prespore cells but after a time of migration stained cells appear in the prestalk region; reflecting a natural turnover process, whereby a cluster of anteriorly located prestalk cells, the pstAB cells, periodically commit prematurely to stalk cell differentiation, are discarded from the rear of the slug and replaced by the forward movement and re-differention of prespore cells (Abe et al., 1994; Harwood et al., 1991; Sternfeld, 1992).

This cellular flow was discovered using vital dyes and stable reporter proteins but was elegantly verified using unstable reporter constructs (Detterbeck et al., 1994). PspA:ile-gal is similar in structure to pspA:gal, except that it encodes a mutant form of $\beta$ galactosidase that is processed in the cell to reveal an ile residue at the $\mathrm{N}$ terminus (Detterbeck et al., 1994). Such a protein has a lower half-life than the parental form of the protein. When this reporter construct is transformed into cells and analysed during slug migration the clear demarcation between prepore and prestalk cells is maintained. The logical conclusion is that when prespore cells move forward they re-specify as prestalk cells, cease to transcribe $p s p A$ and the unstable reporter protein rapidly disappears from the cell. When the pspA:ile-gal construct is expressed in smdA-slugs staining is confined to the prespore region (Fig. 3B). One strong prediction from this model is that the mis-localisation be progressive; that using the stable reporter patterning should

be normal at very early stages of prestalk-prespore segregation. This is fully borne out in that tipped smdA- mounds expressing pspA:gal display correct patterning (Fig. 3C).

\section{Discussion}

We isolated SmdA by affinity chromatography using two separate regions of the $p s p A$, prespore-specific promoter. However, many proteins were identified as binding to each fragment and our subsequent analyses tend to suggest that the isolation of SmdA was serendipitous. We tested the possibility that SmdA, like Smyd3 (Hamamoto et al., 2004), binds directly to DNA, by expressing SmdA in E. coli. We could not detect binding to $p s p A$ promoter sequences in a gel retardation assay (unpublished results). Nor was there any discernible effect of the $s m d A$ null mutation on total $p s p A$ gene expression at the slug stage. Analysis of the $s m d A$ null did, however, reveal an apparent topological change in $p s p A$ reporter gene expression.

In the smdA-strain, just as in the ampA-mutant of Varney et al., (2002), stable $\beta$-galactosidase reporter protein is present, ectopically, in the prestalk region of standing and migrating slugs. This seemed to suggest that SmdA might be a co-repressor, interacting with a negative regulator of transcription, However at early stages of slug formation, or in mature slugs expressing an unstable prespore marker, staining is restricted to the prespore region. A likely explanation for these observations is that a gene regulated by SmdA is essential to stabilise the differentiation state of the prespore cells; so that in the absence of SmdA cells rapidly re-differentiate as prestalk cells that then sort to the prestalk region. A very similar function has been posited for the product of the triA gene (Jaiswal et al., 2006). If correct, it would be of interest to profile gene expression patterns in the parental and null strains for both triA and $s m d A$ to identify genes involved in stabilising prespore cell differentiation.

\section{Materials and Methods}

Cell growth, transformation, development and $\beta$-galactosidase staining Dictyostelium discoideum cells strain Ax-2 (Gerisch isolate) were grown in axenic medium at 22C. Cells growing at a density of $2 \times 10^{6} \mathrm{cell} / \mathrm{ml}$ were transformed by electroporation. For development cells were harvested and washed in $\mathrm{KK} 2$ (16.1 $\mathrm{mM} \mathrm{KH}_{2} \mathrm{PO}_{4}, 3.7 \mathrm{mM} \mathrm{K}_{2} \mathrm{HPO}_{4} \mathrm{pH}$ 6.2) and plated on $1.2 \%$ water agar plates at a density of $6 \times 10^{5} \mathrm{cells} / \mathrm{cm}^{2}$. Transformant pools, transformed with lacZ markers, were fixed and stained for $\beta$-galactosidase at the first finger or migratory slug stages.

\section{Acknowledgements}

The work was initially funded by an MRC project grant (MRC G0600244 to JGW) and was completed with the support of a Wellcome Trust program grant (082579/Z to JGW).

\section{References}

ABE T., EARLY A., SIEGERT F., WEIJER C., WILLIAMS J., 1994. Patterns of cell movement within the Dictyostelium slug revealed by cell type-specific, surface labeling of living cells. Cell. 77: 687-699. 
BROWN M. A., SIMS R. J., 3RD, GOTTLIEB P. D., TUCKER P. W., 2006. Identification and characterization of Smyd2: a split SET/MYND domain-containing histone H3 lysine 36-specific methyltransferase that interacts with the Sin3 histone deacetylase complex. Mol Cancer. 5: 26.

DETTERBECK S., MORANDINI P., WETTERAUER B., BACHMAIR A., FISCHER K., MACWILLIAMS H. K., 1994. The 'prespore-like cells' of Dictyostelium have ceased to express a prespore gene:Analysis using short-lived beta-galactosidases as reporters. Development. 120: 2847-2855.

EARLY A. E., WILLIAMS J. G., 1989. Identification of sequences regulating the transcription of a Dictyostelium gene selectively expressed in prespore cells. Nucl. Acids Res. 17: 6473-6484.

GAUDET P., WILLIAMS J. G., FEY P., CHISHOLM R. L., 2008. An anatomy ontology to represent biological knowledge in Dictyostelium discoideum. BMC Genomics. 9: 130.

HAMAMOTO R., FURUKAWA Y., MORITA M., IIMURA Y., SILVA F. P., LI M., YAGYU R., NAKAMURA Y., 2004. SMYD3 encodes a histone methyltransferase involved in the proliferation of cancer cells. Nat Cell Biol. 6: 731-740.

HARWOOD A. J., EARLY A. E., JERMYN K. A., WILLIAMS J., 1991. Unexpected localisation of cells expressing a prespore marker of Dictyostelium discoideum. Differentiation. 46: 7-13.

HuANG J., PEREZ-Burgos L., PlACEK B. J., SENGUPTA R., RICHTER M.,
DORSEY J. A., KUBICEK S., OPRAVIL S., JENUWEIN T., BERGER S. L., 2006. Repression of p53 activity by Smyd2-mediated methylation. Nature. 444:629-632.

JAISWAL, J. K., MUJUMDAR, N., MACWILLIAMS, H. K., NANJUNDIAH, V., 2006. Trishanku, a novel regulator of cell-type stability and morphogenesis in Dictyostelium discoideum. Differentiation 74: 596-607.

KIM H., HEO K., KIM J. H., KIM K., CHOI J., AN W., 2009. Requirement of histone methyltransferase SMYD3 for estrogen receptor-mediated transcription. J Biol Chem. 284: 19867-19877.

REA S., EISENHABER F., O'CARROLL D., STRAHL B. D., SUN Z. W., SCHMID M., OPRAVIL S., MECHTLER K., PONTING C. P., ALLIS C. D., JENUWEIN T., 2000. Regulation of chromatin structure by site-specific histone $\mathrm{H} 3$ methyltransferases. Nature. 406: 593-599.

STERNFELD J., 1992. A study of pstB cells during Dictyostelium migration and culmination reveals a unidirectional cell type conversion process. W.R. Arch. Dev. Biol. 201: 354-363

TAN X., ROTLLANT J., LI H., DE DEYNE P., DU S. J., 2006. SmyD1, a histone methyltransferase, is required for myofibril organization and muscle contraction in zebrafish embryos. Proc Natl Acad Sci USA. 103: 2713-2718.

VARNEY, T. R., HO, H., PETTY, C., AND BLUMBERG, D. D. 2002. A novel disintegrin domain protein affects early cell fate specification and pattern formation in Dictyostelium. Development 129: 2381-2389. 


\section{Further Related Reading, published previously in the Int. J. Dev. Biol.}

See our recent Special Issue Placenta edited by Joan S. Hunt and Kent L. Thornburg at: http://www.ijdb.ehu.es/web/contents.php?vol=54\&issue=2-3

Interplay between DNA methylation, histone modification and chromatin remodeling in stem cells and during development Kohta Ikegami, Jun Ohgane, Satoshi Tanaka, Shintaro Yagi, and Kunio Shiota Int. J. Dev. Biol. (2009) 53: 203-214

Chromatin remodeling in plant development José A. Jarillo, Manuel Piñeiro, Pilar Cubas and José M. Martínez-Zapater Int. J. Dev. Biol. (2009) 53: 1581-1596

The MADS-box transcription factor SRFA regulates different aspects of Dictyostelium discoideum development N Moreno, JJ Vicente, R Escalante, L Sastre Int. J. Dev. Biol. (2001) 45: 9911-9911

Regulation of cell differentiation and pattern formation in Dictyostelium development I Takeuchi, M Tasaka, K Okamoto and Y Maeda

Int. J. Dev. Biol. (1994) 38: 311-319

Remodeling of sperm chromatin induced in egg extracts of amphibians C Katagiri and K Ohsumi

Int. J. Dev. Biol. (1994) 38: 209-216

5 yr ISI Impact Factor $(2009)=3.253$

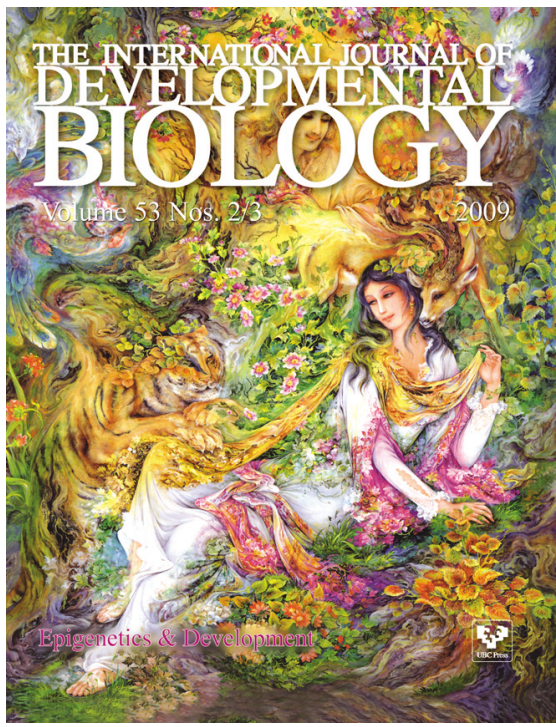

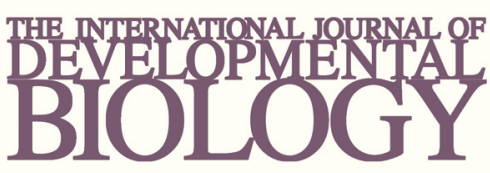

Volume 54 Nos. 6/7
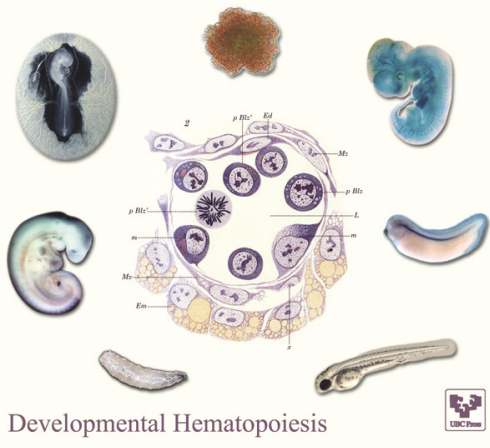

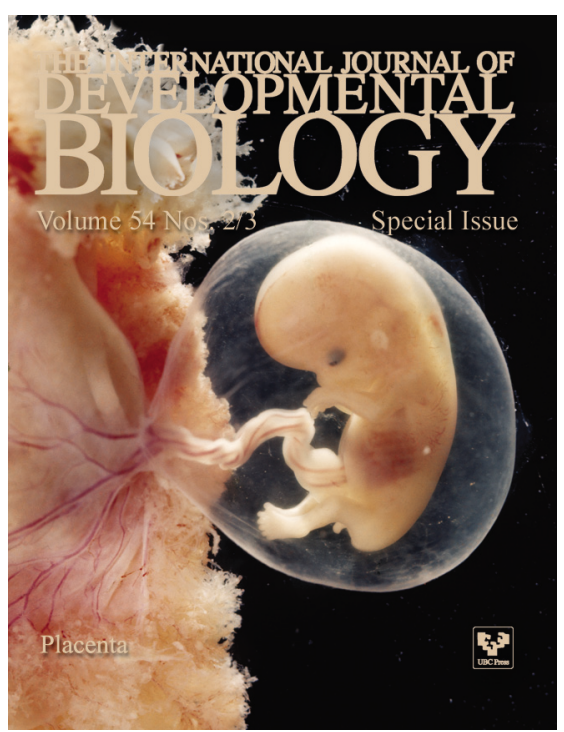

